\title{
Endoscopy after esophagectomy: Doctors' dilemma
}

\author{
Jian-Yong Ding, MD, PhD
}

From the Department of Thoracic Surgery, The Affiliated Zhongshan Hospital of Fudan University, Shanghai,
China.
Disclosures: Author has nothing to disclose with regard to commercial support.
Received for publication May 5, 2017; accepted for publication May 11, 2017; available ahead of print June 21,
2017.
Address for reprints: Jian-Yong Ding, MD, PhD, Department of Thoracic Surgery, The Affiliated Zhongshan Hos-
pital of Fudan University, No. 180 Fenglin Rd, Shanghai 200032, China (E-mail: ding.jianyong @ zs-hospital.
sh.cn).
J Thorac Cardiovasc Surg 2017; $154: 1161-2$
0022-5223/\$36.00
Copyright @ 2017 by The American Association for Thoracic Surgery
http://dx.doi.org/10.1016/j.jtcvs.2017.05.034

Complications after esophagectomy significantly affect outcomes, including perioperative mortality and costs. Anastomotic leak and conduit ischemia remain the most serious complications, and early recognition and appropriate initial treatment are essential. Computed tomography scan, contrast esophagography, and endoscopy will be the candidate options to assess the situation. ${ }^{1,2}$ Of particular importance is endoscopy after esophagectomy to differentiate leaks to conduit ischemia. Endoscopy also can be used therapeutically to introduce stents into a leaking anastomosis. ${ }^{3,4}$ The application of endoscopy varies among institutions and doctors, with limitations mostly owing to safety concerns (Figure 1).

The timing of endoscopy after esophagectomy is a critical factor for safety concerns. Generally speaking, it is almost undisputable for an endoscopy examination to be performed 3 weeks after esophagectomy, which is also widely used in actual clinical practice owing to its relative safety. The anastomasis and conduit are vulnerable early after esophagectomy. Most morbidity, including anastomasis leakage and necrosis of the conduit, occurs 2-7 days after

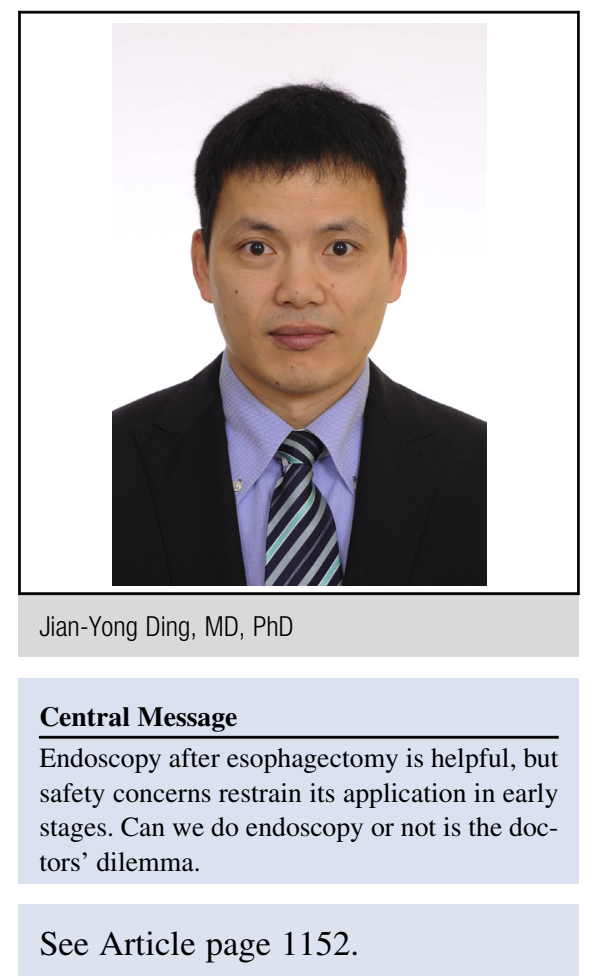

esophagectomy. ${ }^{5}$ Indeed, few relevant studies have reported an endoscopy examination within 3 weeks after esophagectomy, whereas some clinical retrospective studies from single institutions have indicated that it is a safe procedure. ${ }^{6,7}$ Nevertheless, it is not sufficiently convincing and cannot eliminate the safety concerns of doctors. Moreover, there
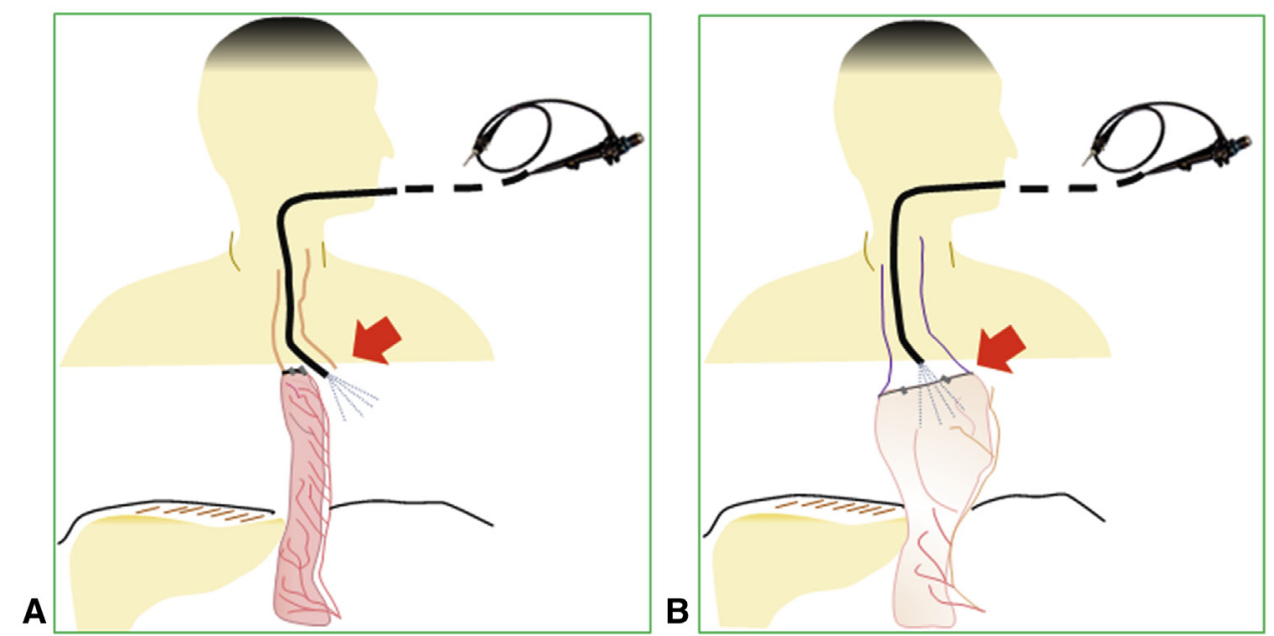

FIGURE 1. Potential risks of endoscopy examination after esophagectomy. A, Mechanical injury from endoscopy examination. B, Air insufflation injury to the anastomasis and staple lines of gastric conduit, as well as compromising blood flow. 
has been no previous animal model or clinical trial to determine the safe parameters of insufflation for esophagectomy endoscopy in early stages. When problems occur early after esophagectomy, it is the doctors' dilemma as to whether the endoscopy should be performed.

The paper by Raman and colleagues ${ }^{8}$ reports an interesting study on an in vivo porcine model. In the first part of the study, the authors assessed the potential mechanical risk to the anastomasis or the stapled lines of gastric conduit of endoscopy. In 15 models, they did not see any overt visible disruption to the anastomasis, conduit staple lines, or gastric mucosa. With progressive insufflation, the intralumen pressure reached a plateau that was far below the risky pressure that we defined in previous study. In the second part of the study, the authors investigated the flow and perfusion of the gastric conduit with endoscopy insufflation after esophagectomy. Endoscopy examination did not disturb blood flow and oxygen saturation of the conduit. The results of that study give us great confidence in the safety of gastroscopy after esophagectomy.

We also note some limitations of the study. First, the tests were conducted immediately after esophagectomy, and we wonder if the anastomasis is strong and the conduit ischemia time is adequate. In the model, all cases were chest-abdominal approaches, and the anastomasis is in the chest with an open procedure, which can mimic the IvorLewis procedure, but not the McKeown procedure. The air insufflation time in this study is short, and we did not know about the situation when the procedure extended a longer time. We also have to keep in mind that research is limited.

In conclusion, this study provides insight into the safety parameters of endoscopy examination after esophagectomy with an in vivo porcine model, thereby paving the way for studies aimed at understanding how and when endoscopy can be safely performed in an early stage in patients undergoing esophagectomy.

I thank $\mathrm{Ai}-\mathrm{Wu} \mathrm{Ke}$ for his assistance in creating the figure.

\section{References}

1. Crestanello JA, Deschamps C, Cassivi SD, Nichols FC, Allen MS, Schleck C, et al. Selective management of intrathoracic anastomotic leak after esophagectomy. $J$ Thorac Cardiovasc Surg. 2005;129:254-60.

2. Briel JW, Tamhankar AP, Hagen JA, DeMeester SR, Johansson J, Choustoulakis E, et al. Prevalence and risk factors for ischemia, leak, and stricture of esophageal anastomosis: gastric pull-up versus colon interposition. J Am Coll Surg. 2004; 198:536-41; discussion 541-2.

3. D'Cunha J, Rueth NM, Groth SS, Maddaus MA, Andrade RS. Esophageal stents for anastomotic leaks and perforations. J Thorac Cardiovasc Surg. 2011;142: $39-46$.

4. Trentino P, Pompeo E, Nofroni I, Francioni F, Rapacchietta S, Silvestri F, et al. Predictive value of early postoperative esophagoscopy for occurrence of benign stenosis after cervical esophagogastrostomy. Endoscopy. 1997;29:840-4.

5. Pross M, Manger T, Reinheckel T, Mirow L, Kunz D, Lippert H. Endoscopic treatment of clinically symptomatic leaks of thoracic esophageal anastomoses. Gastrointest Endosc. 2000;51:73-6.

6. Page RD, Asmat A, McShane J, Russell GN, Pennefather SH. Routine endoscopy to detect anastomotic leakage after esophagectomy. Ann Thorac Surg. 2013;95: 292-8.

7. Maish MS, DeMeester SR, Choustoulakis E, Briel JW, Hagen JA, Peters JH, et al. The safety and usefulness of endoscopy for evaluation of the graft and anastomosis early after esophagectomy and reconstruction. Surg Endosc. 2005;19:1093-102.

8. Raman V, MacGlaflin CE, Erkmen CP. Non-invasive positive pressure ventilation following esophagectomy: safety demonstrated in a pig model. Chest. 2014;147: 356-61. 